\title{
A review of sprinkler system effectiveness studies
}

\author{
Kevin Frank ${ }^{1 *}$, Neil Gravestock ${ }^{2}$, Michael Spearpoint ${ }^{1}$ and Charles Fleischmann ${ }^{1}$
}

\begin{abstract}
A lack of information on the effectiveness of fire safety systems, including sprinklers, has been noted as being a limiting factor in the development of performance-based fire safety design. Of the fire safety systems available, sprinkler operation has been studied most extensively. This paper reviews the information currently available on sprinkler effectiveness in fires. Two approaches are generally taken for estimating sprinkler effectiveness:

component-based approaches using a fault tree or similar method and system-based approaches using fire incident data where sprinklers were present. In this paper, sprinkler system component data and effectiveness estimates from system-based studies have been compiled and tabulated, with a comparison of the merits of the two approaches. Recommendations for using the data for design purposes are made, including considerations for uncertainty and using a hybrid system/component approach for specific sprinkler system comparisons. These recommendations provide input on the reliability of systems in the development of performance-based fire safety design methods.
\end{abstract}

Keywords: Sprinklers; Effectiveness; Reliability; Suppression

\section{Introduction}

Building fire safety design involves evaluation of the likelihood and consequences or risk of potential fire events that may impact the fire safety objectives of the building. Objectives are set by regulation and/or by the owner and/or user and/or insurer of the building. These objectives universally include an adequate (but usually unquantified) level of safety for the occupants of the building, some facilitation of firefighting should a fire occur in the building, and some limitation of the physical damage that would result from a fire in the building.

Systems are commonly installed in buildings to provide a cost-effective mitigation of the risk to life safety and/or property destruction, etc. The contribution and interactions of each of the systems towards achieving the objectives should be known. This either requires historical data that directly addresses effectiveness or historical data on the reliability of the system (the probability that the system will operate as required at any time) and on the effect of the correctly operating system (the efficacy) on each of the objectives that it is intended to address. Some

*Correspondence: kfrank81@gmail.com

1 University of Canterbury, Christchurch, New Zealand

Full list of author information is available at the end of the article systems, while positive in relation to some objectives, may be negative in relation to other objectives.

In the move towards risk- and performance-based fire safety design (Notarianni and Fischbeck 1999) identified "7 major barriers to determining and documenting achievement of agreed upon levels of fire safety", one of which was that "no standardized methods exist to incorporate reliability of systems." At an October 2006 meeting in Wellington, New Zealand, the International Forum of Fire Research Directors which includes members from the Building Research Association of New Zealand (BRANZ), the Commonwealth Scientific and Industrial Research Organisation (CSIRO), the National Institute of Standards and Technology (NIST), FM Global, the National Research Council of Canada (NRCC), and the Society of Fire Protection Engineers (SFPE) among others, listed as 2 of their top 5 research priorities (Grosshandler 2006):

- "to improve our ability to predict the impact of active fire protection systems on the fire growth and fate of combustion products; and

- to estimate the various contributions to uncertainty and to incorporate them into hazard and risk analyses"

\section{望 Springer}

(c) 2013 Frank et al.; licensee Springer. This is an Open Access article distributed under the terms of the Creative Commons Attribution License (http://creativecommons.org/licenses/by/2.0), which permits unrestricted use, distribution, and reproduction in any medium, provided the original work is properly cited. 
for developing the next generation of performance-based fire safety design tools (Croce et al. 2008). (Beyler 1999) stated that "the reliability of fire suppression systems remain[s] a subject of great uncertainty due to our unwillingness or inability to assess reliability from historical data." A New Zealand example where the inability to quantify fire safety system effectiveness was a substantial barrier to evaluating alternative fire designs occured in the single means of escape determinations in 2005-2006, where it was noted that "there is as yet inadequate data for fire engineering to achieve the accuracy that is expected from, for example, structural engineering... In particular, the probabilities used for a fire analysis must be based on fire statistics derived from a comparatively small data pool... that applies not only to fire scenarios but also to the proper functioning of critical systems including the sprinklers" (Department of Building and Housing 2005).

Automatic fire sprinkler systems are designed to activate if a fire develops in their area of protection and limit or suppress the further development of the fire. Thus, when evaluating a building design that incorporates sprinklers for fire safety, knowledge of the effectiveness of sprinkler systems in reducing the risk from fire is important. Similarly the development of codified approaches to the design of systems (e.g. sprinkler standards) benefit from the knowledge of the effectiveness of the systems currently in use.

Different methods of analysing risk to fire safety in buildings have been developed. One method that has been described in fire safety engineering guidelines (British Standards Institution 2003) and used in fire risk analysis case studies in Australia (Thomas et al. 1992) and New Zealand (Enright 2003) (among others) is to discretise expected fire outcomes using an event tree. A typical event tree can be seen in Figure 1. Branches on the event tree represent mutually exclusive outcomes from individual events, with the probability of each event outcome being represented by a value or distribution. Where sprinklers are included in the design, the probability of successful sprinkler operation can be included as an event.

Specialised software has also been developed for evaluating fire risk. Probability estimates of sprinkler effectiveness and/or reliability may be required in a similar manner to the event tree approach (Yung and Benichou 2000).

One difficulty with using the approaches discussed above is determining the values that should be used for the probability of the events, such as the event that the sprinkler system operates successfully. Additionally, it can be difficult to determine how a value should be adjusted if the system is modified, which is particularly important in comparative risk assessment. An example involving sprinklers that has been encountered in New Zealand was how the probability of successful sprinkler operation should be adjusted if a single towns' main water supply was supplemented with a secondary tank supply (Department of Building and Housing 2005).

In fire and smoke spread models (such as zone and field models) used for fire safety analysis, sprinklers are generally assumed to have an effect on the heat release rate of the fire. A common assumption for the performance of a sprinkler system in a performance-based design is that the heat release rate of the fire will not exceed the heat release rate at the time of sprinkler activation, as shown in Figure 2, typically described as controlling the fire. This approach is described in the International Fire Engineering Guidelines (Donaldson et al. 2005), and is also recommended in other performance-based approaches such as the New Zealand Verification Method (Department of Building and Housing 2012). As it is difficult to quantify sprinkler performance in real fires in terms of heat release rate, a number of other criteria have been used, such as:

- fire containment to room of origin

- number of sprinklers activated

- amount of damage to structure and property

- required amount of fire service intervention

- occupant injuries or fatalities

The differences in these criteria make it difficult to apply the reported sprinkler effectiveness probabilities to fire risk modelling. The use of these criteria in the studies identified in the literature is discussed in Section "System-based studies".

Sprinkler performance in fires may depend on the following factors:

- sprinkler and sprinkler system characteristics

- age and deterioration

- inspection, testing, and maintenance

- standards and technology available at the time of design

- modifications

- changes in building use or hazard being protected

- building design

- other building systems, such as heating and ventilation

- water supply changes

among others. A number of studies have been published which provide information on sprinkler system effectiveness. Since automatic sprinkler systems were originally invented and developed in the 1800s (Grant 1996), there has been debate as to how effective they are. An early reference to estimates of sprinkler effectiveness can be found in the Preliminary Report of the New York State Factory Investigating Commission, which was released in 1912 following the Triangle Shirtwaist fire. This report stated that (New York State Factory Investigating Commission 1912): 


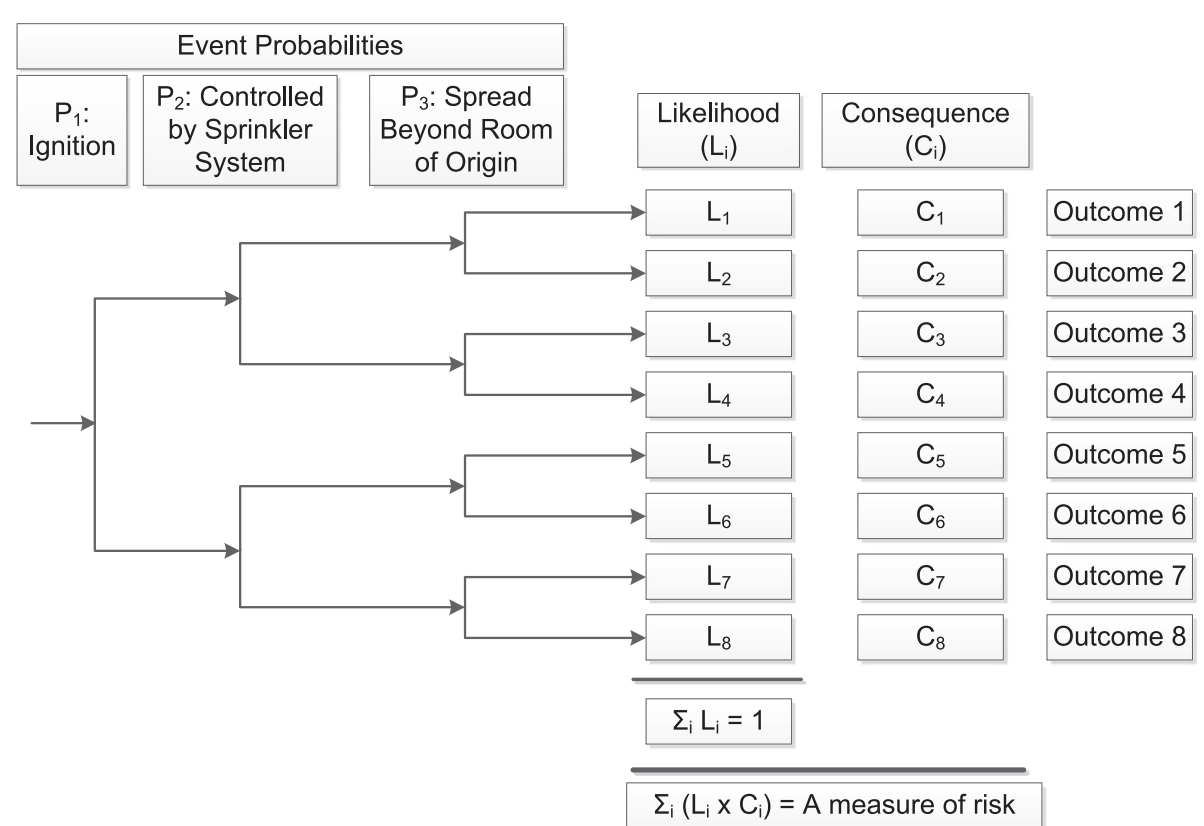

Figure 1 Typical event tree for $\mathbf{3}$ events, with event probabilities $\mathbf{P}_{\mathbf{1}}-\mathbf{P}_{\mathbf{3}}$. Successful sprinkler fire control is represented as the second event.

"Testimony as to the efficacy of sprinkler systems varies, but the lowest estimate of their proper working is 75 per cent and the highest 95 per cent."

It is unknown what information this testimony was based on. As the 20th century progressed, several other organisations recorded information on the operation of sprinkler systems. Some of these studies have been used by the examples of risk-informed fire safety engineering previously discussed in this paper. This paper reviews the information currently available from studies on sprinkler system effectiveness in the context of using this information for building fire safety design. This review does not generally attempt to judge the value of existing studies as

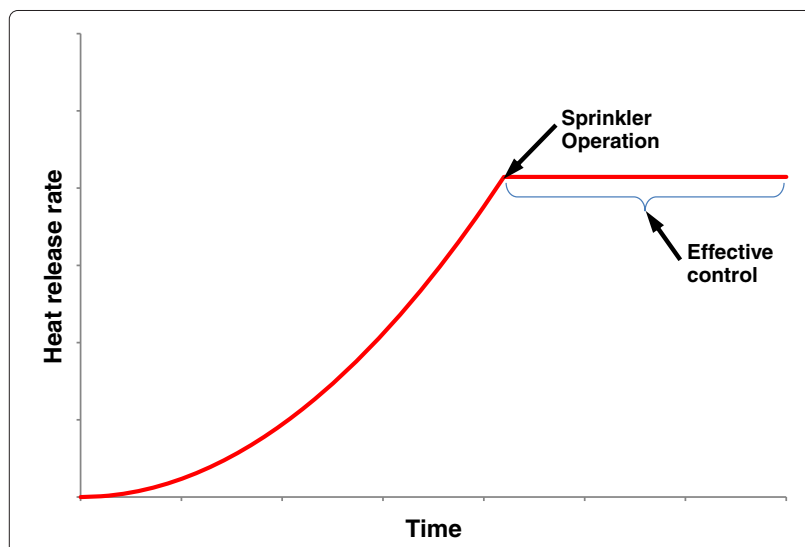

Figure 2 A commonly assumed heat release rate curve for sprinkler fire control. that judgement will depend on the context of the approach to obtain the data and the data application.

\section{Definitions}

There are several different terms used to describe the successful operation of fire safety systems. For the purposes of this study, "reliability" is defined as the probability that a sprinkler system will activate and supply water to a fire demand. "Efficacy" is defined as the probability that the sprinkler system will affect the development of the fire as specified in the system design objectives, given that it operates. "Effectiveness" is a term describing the overall performance of the sprinkler system, combining both the reliability and efficacy. These definitions have been used in other studies on sprinkler systems, such as those by (Thomas 2002). "Availability" describes the probability that the system will not be out of service for inspection, testing, or maintenance, and is included in reliability.

This review does not consider the potential for sprinkler systems to fail when there is no fire present. Such situations may include rupture due to freezing or mechanical damage leading to water damage, or activation in non-fire conditions. These types of failure are not generally directly considered in a building fire risk analysis, but they may be relevant for other purposes, such as a cost/benefit analysis for installing specific fire protection systems.

Sprinkler system reliability and effectiveness as defined do not directly translate to impact measures; for example, reduction of property damage or a reduction of fatalities. They are a measure of the ability of the sprinkler system 
to respond and to meet the design objectives, respectively. As an extreme example, a " $100 \%$ effective" sprinkler system would not equate to a $100 \%$ reduction in loss, because a fire must be present and reach sufficient size to activate the sprinkler system as designed and thus there will always be a measure of loss in a sprinklered fire. Impact measures are discussed later in this paper.

\section{Types of sprinkler effectiveness studies}

Two general approaches have been used in previous studies taken to quantify sprinkler effectiveness:

1. Component-based (fault tree)

2. System-based (incident data)

The component-based approach builds an effectiveness estimate for a system from individual component data. The system-based approach estimates the effectiveness of the entire system directly from past performance in actual fire incidents. For design purposes, either approach have been used with data obtained from already installed systems or "expert judgement" estimates if data was deemed to be lacking or insufficient. Expert judgement is not defined in this paper although such estimates are subject to an expertŠs level of expertise and personal biases. This review will compare the effectiveness estimates obtained from component-based approaches and system-based separately, and subsequently attempt to reconcile them to compare differences and similarities between the values obtained through each approach.

\section{Other sprinkler effectiveness review studies}

Sprinkler effectiveness reviews have been conducted by (Bukowski et al. 1999; Feeney 2001; Koffel 2005; Richardson 1985; Smith 1983), and (Sakenaite 2009). Several studies combine a review of other sources and new data, including (Budnick 2001; Finucane and Pinkney 1988), and (Gravestock 2008).

\section{Component-based studies}

Component-based studies of sprinkler performance use estimates of individual component and model a combination of them using some approach, typically a fault tree, to obtain an estimate of the system reliability. These studies typically provide a reliability estimate for the system only since it is difficult to attribute system efficacy to individual components. A notable exception was completed by (Gravestock 2008), who combined estimates of sprinkler efficacy in smouldering, flaming non-flashover, and flashover fires with a reliability fault tree to estimate an overall effectiveness.

Component-based reliability data is either reported as a failure probability per demand or a failure rate for a unit time. The following formula is used to calculate per demand probability from a failure rate:

$$
P(\text { per demand })=1-e^{-\lambda t}
$$

where $\lambda$ is the failure rate and $t$ is the time between maintenance, inspection, or replacement. This equation is found in various sources (for example, (Lees 2005)) and can be used to convert the following component data from failure rate to failure probability per demand, but it assumes the failure rate is constant over time and will depend on the time period used so it is specific to each application. Thus, the data here is included with the same units and type as originally reported in the literature. Care must be exercised comparing seemingly equivalent data as different methods will have been used to obtain the data and/or different criteria nominated to designate failure.

Component-based reliability probabilities can be combined to estimate system reliability through fault trees. A simple fault tree is shown in Figure 3. Individual component reliability probabilities can be combined, or if data on unique failure modes for individual components is known then they can be included as well. Note that the equations shown for the AND and OR logic assume that the reliability probabilities are independent, which may not always be a realistic assumption if there are significant commoncause failure modes. The fault tree used for a specific sprinkler system will depend on the components that are present in the system.

\section{Sprinkler system component data}

Table 1 shows the identified studies that provide sprinkler system component data. Component data has been classified as related to sprinkler head operation (Table 2), sprinkler piping (Table 3), valves (Table 4), pumps (Table 5), water supplies (Table 6), and miscellaneous components (Table 7).

(Moelling et al. 1980) evaluated sprinkler systems in four nuclear power plants using a fault tree approach. Failure was considered to be system failure to operate on demand, and the performance of the sprinkler system after operation was not considered. While specific information for each of the sprinkler systems was not presented, probabilities for 8 failure modes were included. The source of the probabilities used was not made explicit. Two of these were human-based: inadvertently closed valves and failing to trip a manual release. System reliability was found to be most sensitive to the probability of an inadvertently closed valve and the time between inspections.

(Finucane and Pinkney 1988) and (Nash and Young 1991) provided similar failure rates for multiple sprinkler system components, apparently both sourced from 1972 UK Atomic Energy Authority data.

Budnick (Budnick 2001; Hughes Associates, Incorporated 1998) collected inspection, test, and maintenance 


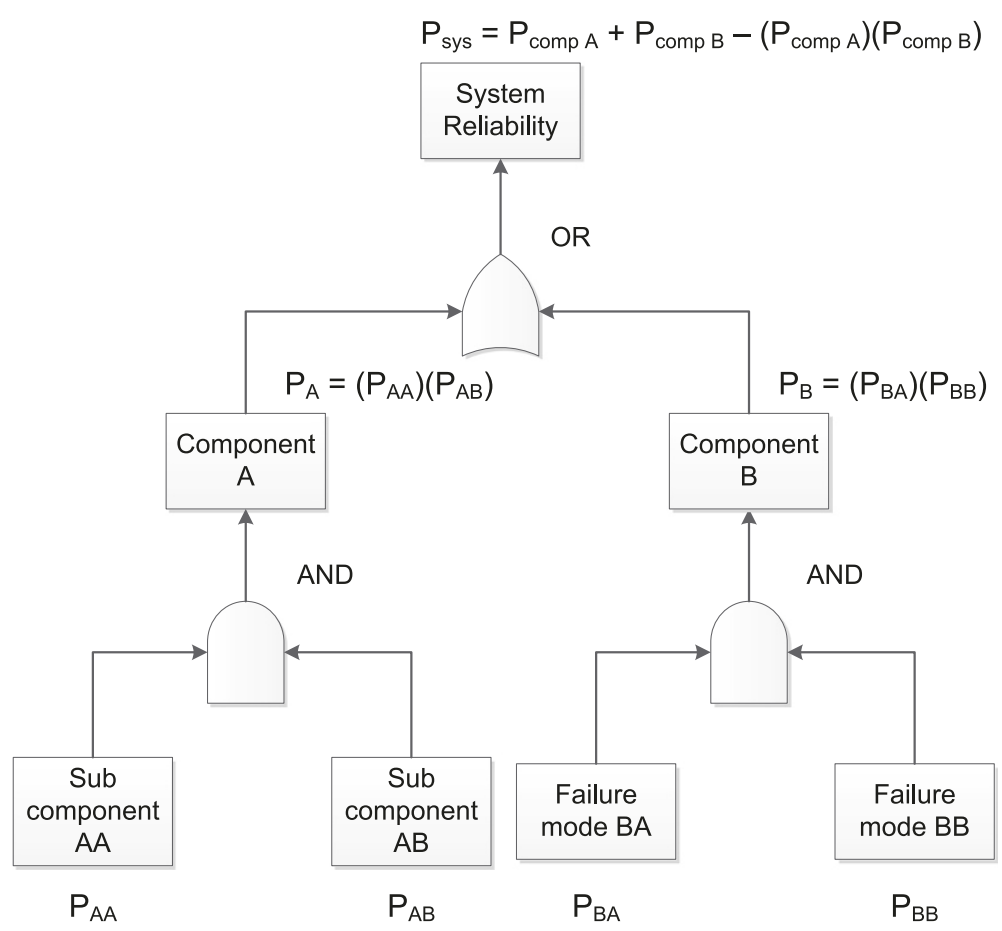

Figure $3 \mathrm{~A}$ basic example of a fault tree. The equations shown assume the probabilities are independent. For the sprinkler system application, included components could be water supplies, sprinkler heads, piping, valves, or other components. Additional components and sub-component levels can be added as required.

Table 1 Studies providing data on sprinkler system component reliability

\begin{tabular}{rccc}
\hline Source & Country & Source of data & Application focus \\
\hline (Watanabe 1979) & Japan & Maintenance records & Japanese buildings \\
(Moelling et al. 1980) & US & Unknown & General \\
(Finucane and Pinkney 1988) & UK & UKAEA Systems Reliability Service & General \\
(Nash and Young 1991) & UK & UKAEA Systems Reliability Service & General \\
(Budnick 2001) & US & Collected from several sprinkler systems & Buildings in Finland \\
& & in one complex over 66 months & (emphasis on nuclear) \\
(Ronty and Keski-Rahkonen 2004) & Finland & Finnish nuclear plant & (emphasis on nuclear) \\
& & electronic maintenance reports, & General \\
(Hauptmanns et al. 2008) & Germany & non-nuclear building inspectionn statistics & fire safety systems \\
(Gravestock 2008) & New Zealand & OREDA, IAUT-AC report & Australian high-rise \\
& & New Zealand fire protection & industry surveys \\
office buildings & Oil and gas \\
(Moinuddin et al. 2009) & Australia & Historical data from 23 Australian * & installations \\
& & high-rise office buildings aged 4 to 36 years* & water supplies
\end{tabular}


Table 2 Data on sprinkler head reliability

\begin{tabular}{|c|c|c|c|c|c|}
\hline Description & Source & Unit & Minimum & Mean & Maximum \\
\hline Removal & (Watanabe 1979) & per demand & & $3.0 \times 10^{-6}$ & \\
\hline Deformation & (Watanabe 1979) & per demand & & $4.61 \times 10^{-4}$ & \\
\hline Leakage & (Watanabe 1979) & per demand & & $3.36 \times 10^{-4}$ & \\
\hline Obstruction (heat and water) & (Watanabe 1979) & per demand & & $1.467 \times 10^{-3}$ & \\
\hline Partition rearrangement & (Watanabe 1979) & per demand & & $4.89 \times 10^{-4}$ & \\
\hline Paint loading & (Watanabe 1979) & per demand & & $6.5 \times 10^{-5}$ & \\
\hline Failure & (Moinuddin et al. 2009) & per demand & & $7.82 \times 10^{-2}$ & \\
\hline Fire detectors fail to function & (Moelling et al. 1980) & per demand & $1.99 \times 10^{-3}$ & $2.97 \times 10^{-3}$ & $4.45 \times 10^{-3}$ \\
\hline Fail to open & (Moelling et al. 1980) & per demand & & $1.00 \times 10^{-6}$ & \\
\hline Failure & (Ronty and Keski-Rahkonen 2004) & failures/year & $1.50 \times 10^{-4}$ & $1.70 \times 10^{-4}$ & $1.80 \times 10^{-2}$ \\
\hline Sprinkler installation & (Ronty and Keski-Rahkonen 2004) & failures/year & $8.0 \times 10^{-3}$ & $1.1 \times 10^{-2}$ & $1.4 \times 10^{-2}$ \\
\hline New (fail dangerous) & (Nash and Young 1991) & failures/year & & $3.10 \times 10^{-2}$ & \\
\hline Old (fail dangerous) & (Nash and Young 1991) & failures/year & & $5.10 \times 10^{-2}$ & \\
\hline Failure to flow water & (Finucane and Pinkney 1988) & failures/year & & $2.0 \times 10^{-2}$ & \\
\hline Water released but & (Finucane and Pinkney 1988) & failures/year & & $8.0 \times 10^{-2}$ & \\
\hline not in intended pattern & & & & & \\
\hline
\end{tabular}

failure data on nine types of component from six sprinkler systems in one facility.

(Hauptmanns et al. 2008) employed the most comprehensive fault tree of the reviewed studies with 60 possible contributing events. Failure probabilities for each event were assigned to a class ranging from 1 to 6 corresponding to an order of magnitude failure probability from 0.1-0.8 to 0.00001-0.0001, respectively. For the specific system considered in the analysis presented in Hauptmann's paper, failure probabilities of $7.1 \times 10^{-4}, 5.5 \times 10^{-2}$, $6.4 \times 10^{-5}$, and $3.1 \times 10^{-3}$ were estimated for the sprinkler piping network, alarm valve station, water supply, and pumps, respectively.

(Ronty and Keski-Rahkonen 2004) looked at maintenance records from sprinkler systems in Finland to estimate sprinkler reliability. The focus of the study was sprinkler systems in nuclear facilities but the authors concluded that there was an insufficient amount of data available from Finnish nuclear facilities so they also collected data from non-nuclear facilities. The values listed in this paper were obtained from the non-nuclear facilities, and Ronty and Keski-Rahkonen note that this data should be used with caution due to "insufficient critical analysis of the data".

(Watanabe 1979) estimated the failure rates of sprinkler subsystems and components from the maintenance records of 97 sprinkler systems in Japan. These systems included a total of 121,991 sprinkler heads and 707 piping arrays. Overall sprinkler reliability, capability (efficacy), availability, and effectiveness were estimated at $98.9 \%$, $99.9 \%, 99.3 \%$, and $98 \%$, respectively.

(Moinuddin et al. 2009) surveyed sprinkler systems in 23 high-rise office buildings in Australia, out of a total of 60 buildings whose staff was contacted for information. Moinuddin observed that the buildings that did not participate may have had a lower standard of maintenance than those that did. The data was used in a fault-tree analysis to estimate sprinkler system reliability for upfeed (water supplied from the base of the building) and downfeed (water supplied by gravity from above) configurations.

Offshore Reliability Data (OREDA) is an organisation that collects reliability data for the petroleum industry. Data is collected on several components that may be relevant to specific sprinkler systems, including deluge valves and pumps (SINTEF 2009). The focus of the dataset is on offshore oil and gas installations which may not be applicable to onshore building sprinkler systems.

(Brammer 2010) conducted a study into the reliability of secondary water supplies as required by the New Zealand sprinkler standard NZS:4541 (2007) (Standards

Table 3 Data on sprinkler piping reliability

\begin{tabular}{rccccc}
\hline Description & Source & Unit & Minimum & Mean & Maximum \\
\hline Pipe array & (Ronty and Keski-Rahkonen 2004) & failures/year & $2.4 \times 10^{-6}$ & $3.3 \times 10^{-6}$ & $4.3 \times 10^{-6}$ \\
Gasket failure & (Budnick 2001) & failures/hour & $5.00 \times 10^{-7}$ & $4.00 \times 10^{-6}$ & $1.20 \times 10^{-5}$ \\
\hline
\end{tabular}


Table 4 Data on sprinkler system valve reliability

\begin{tabular}{|c|c|c|c|c|c|}
\hline Description & Source & Unit & Minimum & Mean & Maximum \\
\hline Sector control valve mishandled & (Watanabe 1979) & per demand & & $2.08 \times 10^{-3}$ & \\
\hline Priming tank gate valve & (Watanabe 1979) & per demand & & $2.47 \times 10^{-3}$ & \\
\hline Deluge fail to open & (Moelling et al. 1980) & per demand & $8.9 \times 10^{-4}$ & $1.9 \times 10^{-3}$ & $3.6 \times 10^{-3}$ \\
\hline Check fail to open & (Moelling et al. 1980) & per demand & $3.0 \times 10^{-5}$ & $1.0 \times 10^{-4}$ & $3.0 \times 10^{-4}$ \\
\hline Closed inadvertently (ICV) & (Moelling et al. 1980) & failures per hour & $6.3 \times 10^{-7}$ & $6.3 \times 10^{-6}$ & $6.3 \times 10^{-5}$ \\
\hline Alarm & (Moinuddin et al. 2009) & per demand & & $2.0 \times 10^{-3}$ & $2.94 \times 10^{-3}$ \\
\hline Main stop & (Moinuddin et al. 2009) & per demand & & $2.3 \times 10^{-3}$ & $3.19 \times 10^{-3}$ \\
\hline Zone isolation & (Moinuddin et al. 2009) & per demand & & $2.2 \times 10^{-2}$ & $3.17 \times 10^{-2}$ \\
\hline \multicolumn{6}{|l|}{ due to tenancy changes } \\
\hline Ordinary stop & (Moinuddin et al. 2009) & per demand & & $6.7 \times 10^{-4}$ & $9.60 \times 10^{-4}$ \\
\hline Non-return & (Moinuddin et al. 2009) & per demand & & $1.1 \times 10^{-3}$ & $1.76 \times 10^{-3}$ \\
\hline Pressure reducing & (Moinuddin et al. 2009) & per demand & & $4.77 \times 10^{-3}$ & $1.04 \times 10^{-2}$ \\
\hline Wet alarm & (Nash and Young 1991) & failures/year & & $4.0 \times 10^{-5}$ & \\
\hline Alternative alarm & (Nash and Young 1991) & failures/year & & $8.0 \times 10^{-5}$ & \\
\hline Main sprinkler stop & (Nash and Young 1991) & failures/year & & $2.0 \times 10^{-4}$ & \\
\hline Non-return & (Nash and Young 1991) & failures/year & & $1.0 \times 10^{-2}$ & \\
\hline Main stop & (Finucane and Pinkney 1988) & failures/year & & $2.3 \times 10^{-3}$ & \\
\hline Non-return & (Finucane and Pinkney 1988) & failures/year & & $1.0 \times 10^{-2}$ & \\
\hline Main sprinkler stop & (Finucane and Pinkney 1988) & failures/year & & $2.0 \times 10^{-3}$ & \\
\hline Wet alarm & (Finucane and Pinkney 1988) & failures/year & & $4.0 \times 10^{-4}$ & \\
\hline Alternative alarm & (Finucane and Pinkney 1988) & failures/year & & $8.0 \times 10^{-4}$ & \\
\hline Post indicating & (Budnick 2001) & failures/hour & & 0 & \\
\hline Alarm check & (Budnick 2001) & failures/hour & & 0 & \\
\hline Outside stem and yoke & (Budnick 2001) & failures/hour & $7.5 \times 10^{-8}$ & $3.6 \times 10^{-7}$ & $8.7 \times 10^{-7}$ \\
\hline Main drain & (Budnick 2001) & failures/hour & & 0 & \\
\hline Inspector's test & (Budnick 2001) & failures/hour & $2.3 \times 10^{-6}$ & $8.3 \times 10^{-6}$ & $1.8 \times 10^{-5}$ \\
\hline Alarm & (Ronty and Keski-Rahkonen 2004) & failures/year & $6.5 \times 10^{-4}$ & $1.2 \times 10^{-3}$ & $2.0 \times 10^{-3}$ \\
\hline \multirow[t]{2}{*}{ Deluge (Critical) } & (SINTEF 2009) & failures/ & 2.8 & 5.8 & 9.4 \\
\hline & & $10^{6}$ calendar hours & & & \\
\hline \multirow[t]{2}{*}{ Deluge (All Modes) } & (SINTEF 2009) & failures/ & 12 & 21 & 31 \\
\hline & & $10^{6}$ calendar hours & & & \\
\hline
\end{tabular}

New Zealand 2007) in some circumstances. He also provided reliability estimates for single sprinkler system water supplies. A case study for the water supply system for Adelaide, Australia was included.

Along with providing a review of other sources and recommending fire safety system component reliability distributions for risk assessment purposes, Gravestock listed sprinkler system deficiency data from inspections in New Zealand, and also collected survey data on 1,293 New Zealand sprinkler systems from 1999 to 2007, shown in Table 8 (Gravestock 2008). Of the buildings included in the survey, $94 \%$ of office buildings, $76 \%$ of apartment buildings, and $89 \%$ of the total building population had sprinkler systems with minor or no defects found. The apartment buildings had a higher proportion of unprotected areas, pump start defects, and inadequate water supplies, although it should be noted that there were only 42 sprinkler systems in apartment buildings included in the survey so there is a large amount of uncertainty due to the small population of buildings. Multi-storey office and apartment buildings accounted for approximately $10 \%$ and $3 \%$ of the survey results, respectively. The category "all building types" included retail, crowd occupancy, healthcare, education, and industrial buildings in addition to office and apartment buildings. 
Table 5 Data on sprinkler system pump reliability

\begin{tabular}{|c|c|c|c|c|c|}
\hline Description & Source & Unit & Minimum & Mean & Maximum \\
\hline Starting device & (Watanabe 1979) & per demand & & $6.84 \times 10^{-3}$ & \\
\hline Fail to start & (Moelling et al. 1980) & per demand & $4.5 \times 10^{-3}$ & $1.4 \times 10^{-2}$ & $2.4 \times 10^{-2}$ \\
\hline Diesel & (Moinuddin et al. 2009) & per demand & & $8.41 \times 10^{-2}$ & $1.21 \times 10^{-1}$ \\
\hline Electric & (Moinuddin et al. 2009) & per demand & & $1.27 \times 10^{-2}$ & $1.90 \times 10^{-2}$ \\
\hline Diesel & (Ronty and Keski-Rahkonen 2004) & failures/year & $8.7 \times 10^{-3}$ & $1.5 \times 10^{-2}$ & $2.3 \times 10^{-2}$ \\
\hline Electric & (Ronty and Keski-Rahkonen 2004) & failures/year & $2.5 \times 10^{-3}$ & $6.2 \times 10^{-3}$ & $1.3 \times 10^{-3}$ \\
\hline \multirow[t]{2}{*}{ Diesel (Critical) } & (SINTEF 2009) & failures/ & 120 & 210 & 310 \\
\hline & & $10^{6}$ calendar hours & & & \\
\hline \multirow[t]{2}{*}{ Diesel (All Modes) } & (SINTEF 2009) & failures/ & 680 & 840 & 1000 \\
\hline & & $10^{6}$ calendar hours & & & \\
\hline \multirow[t]{2}{*}{ Electric (Critical) } & (SINTEF 2009) & failures/ & 24 & 72 & 170 \\
\hline & & $10^{6}$ calendar hours & & & \\
\hline \multirow[t]{2}{*}{ Electric (All Modes) } & (SINTEF 2009) & failures/ & 120 & 210 & 340 \\
\hline & & $10^{6}$ calendar hours & & & \\
\hline
\end{tabular}

\section{Seismic damage to sprinkler system components}

There has been some research conducted into the integrity of sprinkler systems following earthquakes, such as the Northridge event on January 17, 1994 in California (Fleming 1998; Todd et al. 1994), the January 17, 1995 Kobe, Japan earthquake (Sekizawa et al. 2003), and the Canterbury earthquakes in New Zealand in 2010 and 2011 (Houston and Mak 2010), although there has been no data found on sprinkler performance in fires after earthquakes. After the Northridge event, while broken pipes and sheared off sprinklers were found in some instances it was observed that many sprinkler systems were not damaged, particularly in modern systems that met the latest seismic codes and standards. It was estimated that $41 \%$ of the sprinkler systems in Kobe city were damaged after the Kobe earthquake. In the Canterbury earthquakes, several tank water supply sources failed that had been put in place to provide a source of water for the sprinklers if the reticulated supply was compromised. Based on these findings, research into improved design methods for seismic resiliency of tank supplies is ongoing and changes are proposed to the 2013 release of the New Zealand automatic fire sprinkler standard from this work.

\section{System-based studies}

Total system-based studies generally use data from system operation in previous fire events from a population of buildings to estimate measures of effectiveness. The alternative approach is to obtain expert judgement through surveys or Delphi methodology. The estimates of sprinkler effectiveness from these studies are always on a per demand basis since the data comes from actual system demands.

Table 6 Data on sprinkler system water supply reliability

\begin{tabular}{|c|c|c|c|c|c|}
\hline Description & Source & Unit & Minimum & Mean & Maximum \\
\hline Dual supplies & (Brammer 2010) & per demand & $5.0 \times 10^{-9}$ & & $2.4 \times 10^{-5}$ \\
\hline Town main & (Brammer 2010) & per demand & $5.6 \times 10^{-4}$ & & $1.1 \times 10^{-2}$ \\
\hline Pumped supply (diesel) & (Brammer 2010) & per demand & $1.8 \times 10^{-3}$ & & $3.8 \times 10^{-3}$ \\
\hline Elevated tank & (Brammer 2010) & per demand & $1.9 \times 10^{-4}$ & & $1.8 \times 10^{-3}$ \\
\hline Town main & (Moinuddin et al. 2009) & per demand & & $1.87 \times 10^{-4}$ & $3.72 \times 10^{-4}$ \\
\hline Gravity tank & (Moinuddin et al. 2009) & per demand & & $2.28 \times 10^{-4}$ & $2.28 \times 10^{-4}$ \\
\hline Storage tank & (Moinuddin et al. 2009) & per demand & & $4.64 \times 10^{-3}$ & $9.34 \times 10^{-3}$ \\
\hline Water supply line (per m) & (Moinuddin et al. 2009) & per demand & & $1.29 \times 10^{-5}$ & $2.18 \times 10^{-5}$ \\
\hline Town main & (Ronty and Keski-Rahkonen 2004) & failures/year & $2.6 \times 10^{-4}$ & $1.0 \times 10^{-3}$ & $2.5 \times 10^{-3}$ \\
\hline Storage tank & (Ronty and Keski-Rahkonen 2004) & failures/year & & & $6.5 \times 10^{-3}$ \\
\hline Pressure tank & (Ronty and Keski-Rahkonen 2004) & failures/year & $1.0 \times 10^{-3}$ & $2.0 \times 10^{-2}$ & $9.3 \times 10^{-2}$ \\
\hline
\end{tabular}


Table 7 Miscellaneous sprinkler system component data

\begin{tabular}{|c|c|c|c|c|c|}
\hline Description & Source & Unit & Minimum & Mean & Maximum \\
\hline Pressure switch & (Watanabe 1979) & per demand & & $8.99 \times 10^{-4}$ & \\
\hline Down time & (Watanabe 1979) & per demand & & $3.7 \times 10^{-3}$ & \\
\hline Incomplete protection & (Watanabe 1979) & & $1.03 \times 10^{-4}$ & & \\
\hline Alarms fail to function & (Moelling et al. 1980) & per demand & $2.68 \times 10^{-2}$ & $3.62 \times 10^{-2}$ & $4.81 \times 10^{-2}$ \\
\hline Personnel fail to trip manual release & (Moelling et al. 1980) & per demand & & $2.00 \times 10^{-1}$ & \\
\hline Back-up batteries for diesel pump & (Moinuddin et al. 2009) & per demand & & $2.68 \times 10^{-2}$ & $4.92 \times 10^{-2}$ \\
\hline Mains power in building & (Moinuddin et al. 2009) & per demand & & $1.61 \times 10^{-4}$ & $3.11 \times 10^{-4}$ \\
\hline Building power generator & (Moinuddin et al. 2009) & per demand & & $5.24 \times 10^{-3}$ & $1.25 \times 10^{-2}$ \\
\hline Pressure switch & (Moinuddin et al. 2009) & per demand & & $7.82 \times 10^{-3}$ & $1.17 \times 10^{-2}$ \\
\hline Direct brigade alarm & (Moinuddin et al. 2009) & per demand & & $5.27 \times 10^{-3}$ & $9.57 \times 10^{-3}$ \\
\hline Jacking pump & (Moinuddin et al. 2009) & per demand & & $9.85 \times 10^{-3}$ & $1.55 \times 10^{-2}$ \\
\hline Back-up batteries for brigade alarm & (Moinuddin et al. 2009) & per demand & & $2.57 \times 10^{-3}$ & $6.71 \times 10^{-3}$ \\
\hline Alarm motor and gong & (Nash and Young 1991) & failures/year & & $1.6 \times 10^{-2}$ & \\
\hline Accelerator & (Nash and Young 1991) & failures/year & & $7.9 \times 10^{-3}$ & \\
\hline Alarm motor and gong & (Finucane and Pinkney 1988) & failures/year & & $1.6 \times 10^{-2}$ & \\
\hline Accelerator & (Finucane and Pinkney 1988) & failures/year & & $8.0 \times 10^{-3}$ & \\
\hline Flow alarm & (Budnick 2001) & failures/hour & $5.80 \times 10^{-6}$ & $1.50 \times 10^{-5}$ & $2.70 \times 10^{-5}$ \\
\hline Motor gong & (Budnick 2001) & failures/hour & $4.10 \times 10^{-5}$ & $2.50 \times 10^{-5}$ & $1.30 \times 10^{-5}$ \\
\hline Fire department connection (FDC) & (Budnick 2001) & failures/hour & & 0 & \\
\hline
\end{tabular}

A number of past system studies provide an estimate of sprinkler system effectiveness from fire incident data, shown in Table 9. The estimated effectiveness ranges from a minimum of $70.1 \%$ to a maximum of $99.5 \%$, which corresponds to failure rates ranging from 60 failures in 200 fires to 1 failure in 200 fires.

The NFPA has published information on sprinkler system effectiveness in the United States since

Table 8 New Zealand survey data on 1,293 sprinkler systems from 1999 to 2007 (Gravestock 2008)

\begin{tabular}{rccc}
\hline Fault/Issue & Office & Apartment & All building types \\
\hline Inadequate supply & $1.97 \%$ & $2.38 \%$ & $1.70 \%$ \\
Signalling fault & $1.32 \%$ & $2.38 \%$ & $1.08 \%$ \\
Fire service inlet & $0.66 \%$ & $0.00 \%$ & $1.01 \%$ \\
Flow switch & $0.00 \%$ & $0.00 \%$ & $0.23 \%$ \\
Floor isolation & $0.00 \%$ & $0.00 \%$ & $0.08 \%$ \\
Street valve & $3.95 \%$ & $0.00 \%$ & $0.62 \%$ \\
Pump performance & $2.63 \%$ & $0.00 \%$ & $1.47 \%$ \\
Pump start & $3.29 \%$ & $4.76 \%$ & $1.24 \%$ \\
Hydraulic gong & $0.00 \%$ & $0.00 \%$ & $0.15 \%$ \\
Anti-Interference gear & $2.63 \%$ & $0.00 \%$ & $0.85 \%$ \\
Isolated & $0.66 \%$ & $0.00 \%$ & $0.23 \%$ \\
Pressure switch & $0.00 \%$ & $4.76 \%$ & $0.15 \%$ \\
Unprotected areas & $1.97 \%$ & $9.52 \%$ & $2.48 \%$ \\
\hline
\end{tabular}

1897. Estimates of satisfactory or unsatisfactory performance of sprinklers in fires are available from 1897 to 1964 . It was noted that this data set did not include numerous fires extinguished by one or two sprinklers. Information on the rationale for unsatisfactory and satisfactory performance has not been identified for the NFPA data from 1897 to 1925 . The NFPA has noted that reporting categories related to sprinkler performance were modified with the introduction of the National Fire Incident Reporting System (NFIRS) Version 5.0. This change was intended to improve the estimates of sprinkler reliability from the NFIRS data (Rohr and Hall 2005).

(Knudsen and Bygbjerg 2009) presented data from Danish sprinkler system inspection reports from 2001, 2007, and 2008. Deficiencies were placed into four categories:

- Category A: significant defects/deficiencies that will prevent the entire system from operating adequately (must be fixed before approval),

- Category B: defects/deficiencies that will prevent a portion of the system from operating adequately (approval will lapse if not fixed in 2 months),

- Category C: minor defects/deficiencies (must be fixed in 12 months or defect/deficiency is upgraded to category B), and 
Table 9 System-based sprinkler effectiveness studies which provide a direct estimate of sprinkler system effectiveness from past fires in sprinklered buildings

\begin{tabular}{|c|c|c|c|c|c|}
\hline Source & Country & $\begin{array}{l}\text { Data collected } \\
\text { from years }\end{array}$ & $\begin{array}{c}\text { Building } \\
\text { population/location }\end{array}$ & $\begin{array}{l}\text { Number } \\
\text { of events }\end{array}$ & $\begin{array}{c}\text { Nominal reported } \\
\text { effectiveness }\end{array}$ \\
\hline (Tryon and McKinnon 1969) & US & 1897-1924 & United States & 32778 & $95.8 \%$ \\
\hline (Tryon and McKinnon 1969) & US & 1925-1964 & United States & 75290 & $96.2 \%$ \\
\hline (Hall 2006) & US & 1999-2002 & NFIRS 5.0 data & Not Reported & $89 \%$ \\
\hline (Hall 2007) & US & $2002-2004$ & NFIRS 5.0 data & Not Reported & $90 \%$ \\
\hline (Hall 2010) & US & 2003-2007 & NFIRS 5.0 data & 44310 & $91 \%$ \\
\hline (Hall 2012) & US & $2006-2010$ & NFIRS 5.0 data & 47520 & $88 \%$ \\
\hline (US Department of Energy 2004) & US & $1955-2003$ & US DOE facilities & 251 & $98.8 \%$ \\
\hline (Miller 1974) & US & 1970-1972 & FM insured properties & 1355 & $85 \%$ \\
\hline (Powers 1979) & US & 1969-1978 & City of New York & 5709 & $97.0 \%$ \\
\hline (Taylor 1990) & US & 1982-1986 & US general office buildings & 6400 per year* & $81.3 \%$ \\
\hline (Linder 1993) & US & 1988-1993 & Industrial Risk Insurers & 3446 & $94.9 \%$ \\
\hline (Baldwin and North 1971) & UK & 1967-1968 & UK fire brigade data & 619 & $94 \%$ \\
\hline (Marryatt 1988) & Aus/NZ & 1886-1986 & Australia/New Zealand & 9022 & $99.5 \%$ \\
\hline (Frank et al. 2012) & NZ & $2001-2010$ & New Zealand & 1171 & $86 \%$ \\
\hline (Juneja 2004) & Canada & 1995-2002 & Ontario Fire Marshal data & 2536 & $70.1 \%$ \\
\hline
\end{tabular}

* Estimated.

- Category BC: multiple category B or C defects/deficiencies that cumulatively are expected to equate a category A defect/deficiency.

On average, Knudsen and Bygbjerg found that 2\% of inspected Danish sprinkler systems had sufficient problems to not be approved, while $40 \%$ of the inspected systems had zero defects or deficiencies identified.

There are also studies that provide information on sprinkler system effectiveness in terms of effects on the consequences from fire, such as fatalities, injuries, or amount of building floor area consumed by fire. These studies are discussed in a later section.

\section{Definition of sprinkler system effectiveness}

The definition of what constitutes an effective sprinkler system operation in a fire event is not consistent between studies. Marryatt defines "satisfactory" sprinkler operation as limiting the damage to the building and contents to $20 \%$ of the total value involved. He defines "controlled" fires as "those which are extinguished by the sprinkler system by the time the fire brigade arrives, or which would be extinguished eventually without supplementary action by fire brigades or others." This definition is slightly misleading as all fires will eventually extinguish once they have exhausted all available fuel supply. (Hall 2010) states that sprinkler effectiveness should be measured relative to the design objectives of the system, in most cases limiting fire spread to the room of origin.

\section{Reporting of fires that do not activate sprinklers}

A major source of discrepancy when comparing sprinkler effectiveness values between studies is how fires where the sprinkler system is not activated is handled. A sprinkler system may not activate (ie. one or more sprinkler heads operating) in a fire for one of the following reasons:

1. the heat released by the fire was insufficient to activate the sprinkler system (whether or not the sprinkler system was present in the area of origin), or

2. the fire was large enough to activate a sprinkler system but a partial sprinkler system was installed and was not present in the area of fire origin, or

3. the fire was large enough to activate the sprinkler system and one or more sprinklers were present but failed to operate.

At one end of the spectrum, (Marryatt 1988) does not include any fires that did not operate a sprinkler, for any of the three reasons listed above. Sprinklers were reported activated in nearly all of the 49 fires that Marryatt considered the sprinkler system operation to be unsatisfactory, with the possible exception of one incident where the sprinkler system (and building) was completely destroyed in an explosion - in which case water from the broken supply piping still extinguished the fire. This is one factor that likely contributes to high reported values of effectiveness, such as the $99.5 \%$ reported by Marryatt.

At the other end, (Juneja 2004) includes in the operational failures all fires where a sprinkler system was 
installed in the building, including cases where the fire was too small to operate the system and where the fire is remote from the sprinkler system. This contributes to the low sprinkler effectiveness of $70.1 \%$ reported by Juneja, relative to the other studies. To these authors it would seem that the approach used by Juneja is too punitive.

\section{Reasons for sprinkler systems to fail to operate}

Table 10 lists the reported reasons why sprinkler systems failed to operate in the studies where this information was available. For studies that combined failures with ineffective operation, the reported percentage has been normalised to the total number of failures for comparison. The most frequent reason for sprinkler system failure, ranging from $33 \%$ to $100 \%$ of the reported failures, is that the system was shut off. Inappropriate systems, lack of maintenance, and manual intervention are reported at similar frequencies from $5 \%$ to $33 \%$. Damaged components and frozen systems provide the minority of failures, generally near $2 \%$ with one outlier in Power's study damaged components comprised 2 out of 6 failures, which is likely a reflection of the small sample size of failures.

\section{Reasons for ineffective sprinkler system operation}

Table 11 lists the reported reasons why sprinkler systems that operated were ineffective, normalised to the total number of ineffective operations. The most common reason for sprinkler systems to operate ineffectively was that the water did not reach the fire, ranging from 19\% to 55\% of the reported cases. An inappropriate system for the fire was the second most commonly reported reason, followed by not enough water released. These reasons are inter-related, and could have different root causes. For example, a partial coverage system may result in any of these outcomes. A change in occupancy or hazard could also result in all three outcomes: for example, a change in fuel package configuration could result in a portion of the fire being shielded, or a system designed for a light commercial occupancy could be insufficient if the use of the building is changed to storage of high-hazard materials.

(Hall 2010) noted that NFPA estimates of effectiveness "exclude partial systems as identified by reason for failure and ineffectiveness equal to equipment not in area of fire". This approach is not likely taken in the other studies reviewed. It should be noted that reported reasons for sprinkler systems to operate ineffectively may require subjective judgement by the reporter.

\section{Number of sprinklers activated}

Due to the physical evidence available, the number of sprinklers activated is a relatively simple parameter to quantify objectively. However, it is not generally clear how the number of sprinklers activated relates to the effectiveness of the system. PD7974-7:2003 (British Standards
Institution 2003) discusses this issue, noting that some studies consider system operations with up to 200 sprinklers operating effective, and recommends four activated sprinklers as a consistent cut-off for effective operation, stating "no more than four heads operating is the fire size typically used in a fire engineering study". The number of sprinklers activated was reported in a number of the sources that included fire incident data. The available information is summarised in Figure 4. A boxplot of the accumulated percentage of fires where the number of sprinklers or less activated is shown in Figure 5. The boxplot represents the minimum and maximum percentage of sprinklers reported activated with the first and third quartile as the box limits and the median as the horizontal line in the box. To make the figure easier to read the number of sprinklers activated is limited to 10 . The trend for more activated sprinklers can be inferred from Figure 4. The studies range from $71 \%$ to $96 \%$ at the PD79747:2003 recommended effective cut off point of four sprinklers.

Figure 6 plots the reported sprinkler effectiveness percentage versus the percent of fires reported with four or less sprinklers activated. Most studies report a higher frequency of effective sprinkler operation compared with the frequency of fires where four or less sprinklers were reported activated, with the exception of the NFPA 20032007 study. This may be a reflection of the changing occupancies protected by sprinklers, as residential sprinkler systems are designed to support the operation of less sprinklers and more residential buildings are being equipped with sprinkler systems (Hall 2010).

To extend the concept put forth in PD7974-7:2003 of using the number of sprinklers activated as a measure of sprinkler system effectiveness, a comparison was made between the cumulative number of sprinklers reported activated required to reach the effectiveness value quoted each study, where the information was available. This concept can be most readily explained by an example. NFPA data from 1925-1964 (Tryon and McKinnon 1969) reported "satisfactory" sprinkler operation in $96 \%$ of fires, but only $71 \%$ of total fires with sprinklers had four or less sprinklers reported activated. Thus, using the PD79747:2003 criterion of using four or less sprinklers as a benchmark for effective sprinkler system operation, the effectiveness from the 1925-1964 NFPA data would be only $71 \%$, compared to the reported $96 \%$. In order to include the $96 \%$ of fires where sprinklers activated and operation was reported to be satisfactory, fires with up to 36-40 sprinklers activated would need to be included. Figure 7 shows the relationship between the frequency of effective sprinkler operation and the cumulative number of sprinklers reported activated where the frequency equals the effective sprinkler operation frequency. In general, studies reporting a higher frequency of effective 
Table 10 Reported reasons for sprinkler systems to fail to operate

\begin{tabular}{|c|c|c|c|c|c|c|c|c|c|c|}
\hline Source & Years & Types of systems & $\begin{array}{l}\text { Number } \\
\text { of fires }\end{array}$ & $\begin{array}{l}\text { Percent } \\
\text { effective }\end{array}$ & $\begin{array}{l}\text { System } \\
\text { shut off }\end{array}$ & $\begin{array}{l}\text { Inappropriate } \\
\text { system }\end{array}$ & $\begin{array}{l}\text { Lack of } \\
\text { maintenance }\end{array}$ & $\begin{array}{l}\text { Manual } \\
\text { intervention }\end{array}$ & $\begin{array}{l}\text { Damaged } \\
\text { component }\end{array}$ & $\begin{array}{l}\text { System } \\
\text { frozen }\end{array}$ \\
\hline (Tryon and McKinnon 1969) & $1925-1964$ & Not specified & 75290 & $96.2 \%$ & $63 \%$ & $15 \%$ & $15 \%$ & & $3 \%$ & $2 \%$ \\
\hline (Hall 2006) & 1999-2002 & All sprinklers & Not reported & $89.3 \%$ & $65 \%$ & $5 \%$ & $11 \%$ & $16 \%$ & $3 \%$ & \\
\hline (Hall 2007) & $2002-2004$ & All sprinklers & Not reported & $90 \%$ & $66 \%$ & $10 \%$ & $10 \%$ & $20 \%$ & $2 \%$ & \\
\hline (Hall 2010) & $2003-2007$ & All sprinklers & 44310 & $91 \%$ & $53 \%$ & $20 \%$ & $15 \%$ & $9 \%$ & $2 \%$ & \\
\hline (Hall 2012) & $2006-2010$ & All sprinklers & 47520 & $88 \%$ & $63 \%$ & $5 \%$ & $6 \%$ & $18 \%$ & $8 \%$ & \\
\hline (US Department of Energy 2004) & $1955-2003$ & Water-based & 251 & $98.8 \%$ & $33 \%$ & $33 \%$ & & & $33 \%$ & \\
\hline (Powers 1979) & 1969-1978 & High-rise office buildings & 254 & $98.8 \%$ & $100 \%$ & & & & & \\
\hline (Powers 1979) & 1969-1978 & High-rise buildings (excl. office) & 1394 & $98.4 \%$ & $100 \%$ & & & & & \\
\hline (Powers 1979) & 1969-1978 & Low rise buildings & 4061 & $95.8 \%$ & $85 \%$ & $12 \%$ & $3 \%$ & & & \\
\hline \multirow[t]{3}{*}{ (Marryatt 1988) } & 1886-1986 & All sprinklers & 9022 & $99.5 \%$ & $100 \%$ & & & & & \\
\hline & & & Mean & $94.7 \%$ & $73 \%$ & $14 \%$ & $10 \%$ & $15 \%$ & $9 \%$ & $2 \%$ \\
\hline & & & St. dev. & $4.4 \%$ & $23 \%$ & $10 \%$ & $5 \%$ & $4 \%$ & $12 \%$ & N/A \\
\hline
\end{tabular}


Table 11 Reported reasons for sprinkler systems to operate ineffectively

\begin{tabular}{|c|c|c|c|c|c|c|c|c|c|c|c|c|}
\hline Source & Years & $\begin{array}{l}\text { Types of } \\
\text { systems }\end{array}$ & $\begin{array}{l}\text { Water did } \\
\text { not reach } \\
\text { fire }\end{array}$ & $\begin{array}{l}\text { Inappropriate } \\
\text { system for fire }\end{array}$ & $\begin{array}{l}\text { Not enough } \\
\text { water } \\
\text { released }\end{array}$ & $\begin{array}{l}\text { Manual } \\
\text { intervention }\end{array}$ & $\begin{array}{l}\text { Damaged } \\
\text { component }\end{array}$ & $\begin{array}{l}\text { Lack of } \\
\text { maintenance }\end{array}$ & $\begin{array}{l}\text { Exposure } \\
\text { fire }\end{array}$ & $\begin{array}{l}\text { Faulty } \\
\text { building } \\
\text { construction }\end{array}$ & Miscellaneous & Unknown \\
\hline $\begin{array}{l}\text { (Tryon and McKinn } \\
\text { 1969) }\end{array}$ & on 1925-1964 & Not specified & $19 \%$ & $35 \%$ & $21 \%$ & & $4 \%$ & & $4 \%$ & $13 \%$ & $4 \%$ & \\
\hline (Hall 2006) & 1999-2002 & All sprinklers & $55 \%$ & $7 \%$ & $31 \%$ & $2 \%$ & $5 \%$ & & & & & \\
\hline (Hall 2007) & 2002-2004 & All sprinklers & $41 \%$ & $14 \%$ & $29 \%$ & $6 \%$ & $4 \%$ & $6 \%$ & & & & \\
\hline (Hall 2010) & 2003-2007 & All sprinklers & $43 \%$ & $12 \%$ & $31 \%$ & $5 \%$ & $4 \%$ & $4 \%$ & & & & \\
\hline (Hall 2012) & $2006-2010$ & All sprinklers & $53 \%$ & $3 \%$ & $18 \%$ & $9 \%$ & $9 \%$ & $8 \%$ & & & & \\
\hline $\begin{array}{l}\text { (US Department } \\
\text { Energy 2004) }\end{array}$ & of $1955-2003$ & Water-based & & & & None reported & & & & & & \\
\hline (Powers 1979) & 1969-1978 & High-rise office buildings & & & & None reported & & & & & & \\
\hline (Powers 1979) & 1969-1978 & High-rise buildings (excl. office) & & $100 \%$ & & & & & & & & \\
\hline (Powers 1979) & 1969-1978 & Low rise buildings & & $39 \%$ & & & & & $12 \%$ & $15 \%$ & $18 \%$ & $16 \%$ \\
\hline \multirow[t]{3}{*}{ (Marryatt 1988) } & 1886-1986 & All sprinklers & $26 \%$ & $29 \%$ & $2 \%$ & $9 \%$ & & & $13 \%$ & & & $21 \%$ \\
\hline & & Mean & $39 \%$ & $20 \%$ & $32 \%$ & $6 \%$ & $5 \%$ & $6 \%$ & $10 \%$ & $14 \%$ & $11 \%$ & $19 \%$ \\
\hline & & St. dev. & $14 \%$ & $14 \%$ & $30 \%$ & $3 \%$ & $2 \%$ & $2 \%$ & $5 \%$ & $1 \%$ & $10 \%$ & $3 \%$ \\
\hline
\end{tabular}




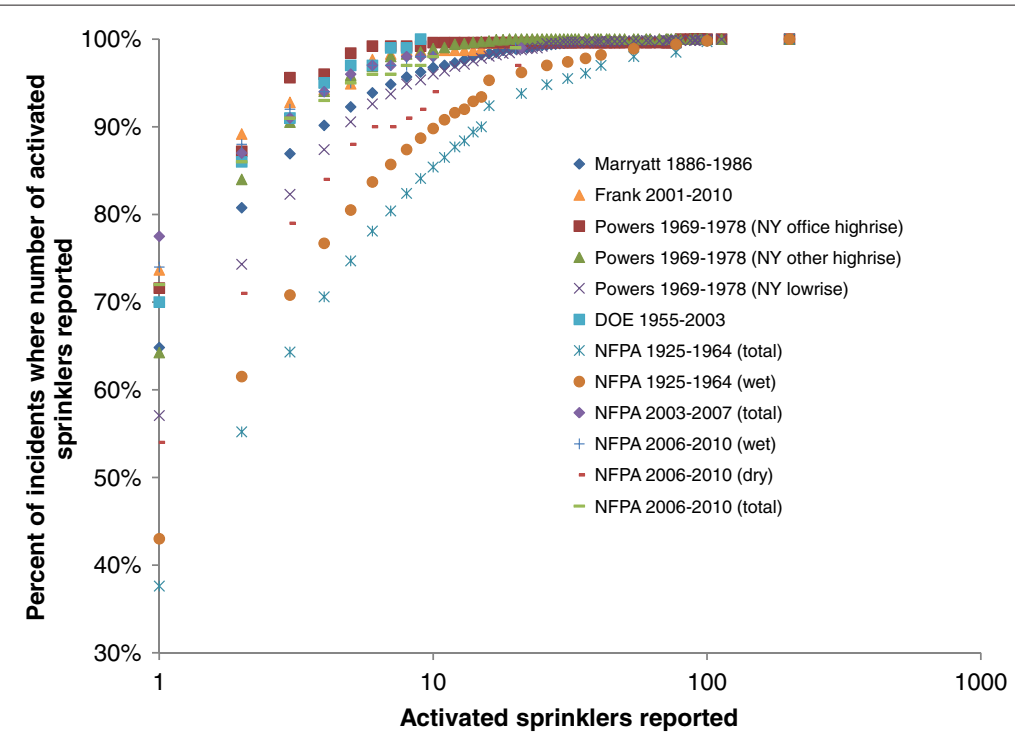

Figure 4 The cumulative percentage of incidents where the number of sprinklers activated were reported.

sprinkler operation required a larger number of activated sprinklers to achieve the stated effectiveness. This is potentially a reflection of the subjective criteria used to define effective sprinkler operation: studies that report high sprinkler effectiveness may have more inclusive criteria for defining effective sprinkler operation.

Typically sprinkler system water supplies are hydraulically designed to support a number of sprinklers or sprinklered area which is a function of the expected fire hazard (Standards New Zealand 2007; Tryon and McKinnon 1969). Baldwin discusses the number of instances where the design number of sprinklers were exceeded for fires in the UK from 1967-1968 (Baldwin and North 1971). A table of the results from this study is shown in Table 12.
Estimates of reduction in fatalities and property damage Several system-based studies estimate the effect of sprinklers on general life safety and property protection objectives such as the number of fatalities or amount of property damage reported in fire incident data. Marryatt's study included eleven fires where fatalities occurred with an operating sprinkler system, only one of which occurred in a fire where the performance of the sprinkler system was considered ineffective, where an explosion occurred and broke the supply main to the system (Marryatt 1988). Of the fires with fatalities in sprinklered buildings, eight were a result of an explosion or flash fire and the remaining three were victims who were intimate with the point of ignition.

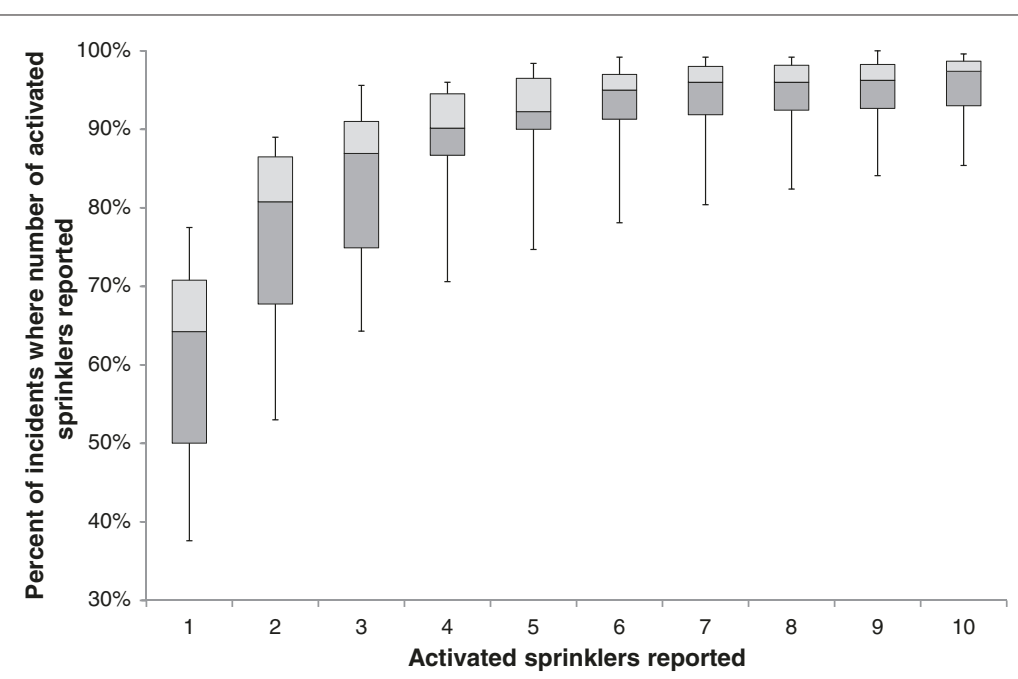

Figure 5 Box plot of cumulative percentage of incidents where the number of sprinklers activated were reported (up to 10 sprinklers activated). 


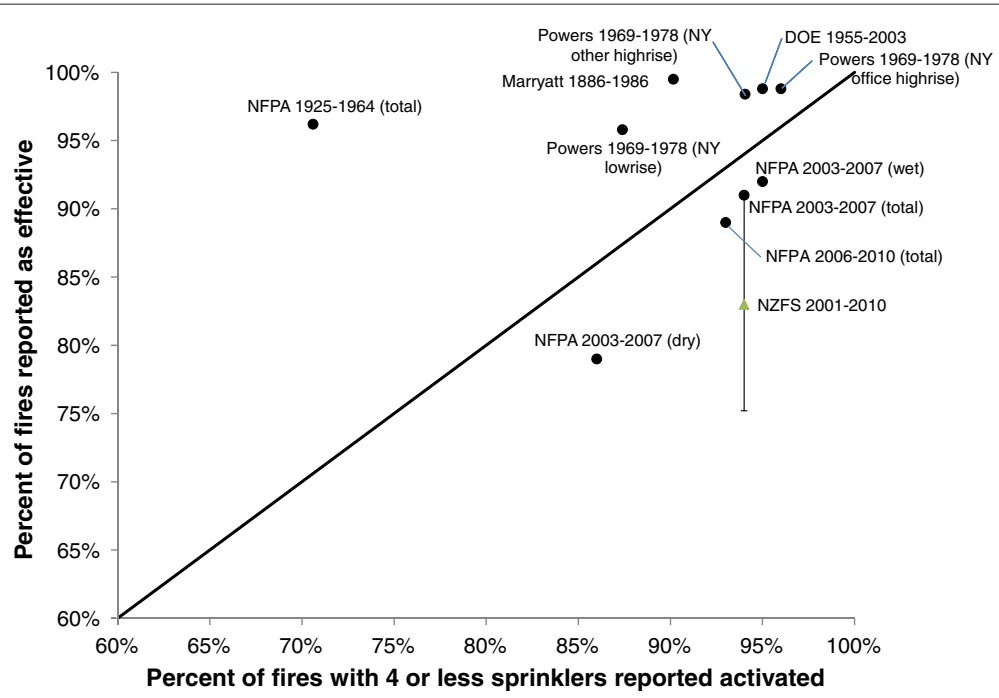

Figure 6 Reported effective sprinkler operation and the frequency of fires reported where four or less sprinklers operated. Wet and dry represent wet and dry pipe sprinkler systems, respectively. The uncertainty in the data from (Frank et al. 2012) is shown by the error bars.

(Thomas 2002) estimated effects of fire safety systems on four objectives including the reduction in fire spread, civilian fatalities, and firefighter losses in fires where various combinations of detectors, sprinklers, and protected construction were present, from historical US NFIRS data. The effects of the systems were compared to a "Base Case" where none of the systems were present. Effectiveness of sprinkler systems was found to vary between -2.46 for the fire spread objective (reported average estimated monetary loss was approximately 2.5 times higher when sprinklers were present compared to the base case)for Storage occupancy buildings and 1.00 for civilian fatalities in Hotels and Motels (reported civilian fatalities were reduced to zero). Negative effectiveness values were also calculated for detectors and protected construction. Thomas concluded that sprinklers were generally better than detectors and fire-rated construction combined, while there was a measurable but sometimes small advantage with all three measures compared with instances where sprinklers were the only system installed.

Thomas also separated NFIRS data for the four objectives mentioned by occupancy, including Public

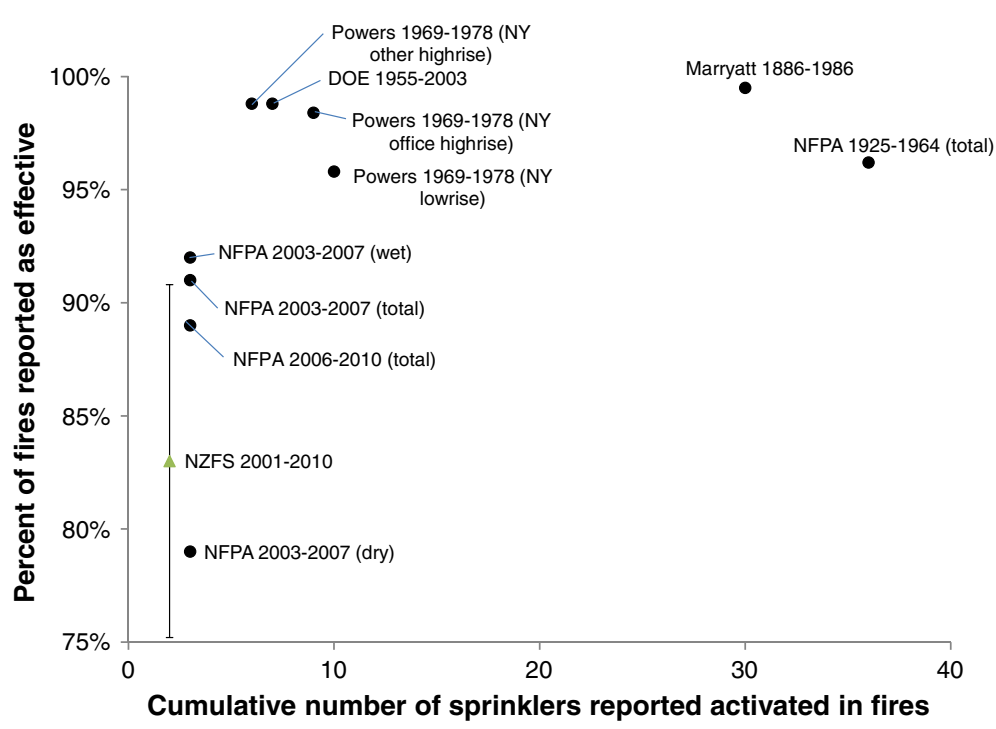

Figure 7 Reported effective sprinkler operation and the cumulative number of sprinklers reported operating at an equivalent frequency to the reported effective sprinkler operation frequency. Wet and dry represent wet and dry pipe sprinkler systems, respectively. The uncertainty in the data from (Frank et al. 2012) is shown by the error bars. 
Table 12 Percentage of fires where the design number of sprinklers was exceeded and where the fire was controlled by sprinklers, from 1967-1968 UK data reported by (Baldwin and North 1971)

\begin{tabular}{|c|c|c|c|c|}
\hline Hazard & $\begin{array}{c}\text { Number of } \\
\text { fires reported }\end{array}$ & $\begin{array}{l}\text { Design number } \\
\text { of sprinklers }\end{array}$ & $\begin{array}{l}\text { Design number of } \\
\text { sprinklers exceeded }\end{array}$ & $\begin{array}{l}\text { Controlled } \\
\text { by sprinklers }\end{array}$ \\
\hline Extra low hazard & 30 & 4 & $23 \%$ & $90 \%$ \\
\hline Ordinary hazard 1 & 8 & 6 & $17 \%$ & $88 \%$ \\
\hline Ordinary hazard 2 & 91 & 12 & $9 \%$ & $93 \%$ \\
\hline Ordinary hazard 3 & 476 & 18 & $6 \%$ & $95 \%$ \\
\hline Extra high hazard & 14 & 29 & $3 \%$ & $79 \%$ \\
\hline
\end{tabular}

Assembly, Institutional, Apartments, Hotels and Motels, Offices, Manufacturing, Educational, 1 and 2 Family Dwellings, Rooming and Boarding, Dormitories, Retail, and Storage. For sprinklers, he found negative effectiveness (measures of the four objectives were worse when sprinklers were present compared to the base case) for civilian injuries in the Public Assembly, Offices, Manufacturing, Educational, Retail, and Storage occupancies; for firefighter injuries in the Storage occupancy; civilian fatalities in the Educational occupancy; and fire spread (measured by average monetary loss) in the Storage occupancy.

Thomas indicated that there may be other factors that influence the apparent effectiveness of the systems considered in his study. For example, he noted that while civilian injuries increased in several occupancies where sprinklers were present, it was impossible to evaluate the severity of the injuries from the reported data, so it was possible that while more injuries occurred when sprinklers were present in some occupancies, many of them may have been less severe. A potential explanation of the increased fire losses noted in Storage occupancy buildings offered by Thomas was that storage buildings with sprinklers may be on average much larger and have much more value associated with the building and contents, although he conceded that this possibility would require more data to verify.

(Melinek 1993b) estimated the number of casualities in the UK if all fires occurred in sprinklered buildings, by relating the number of fatalities to the extent of fire spread in sprinklered and non-sprinklered buildings. It was estimated that the number of fatalities would be reduced by approximately $50 \%$. Melinek also looked at the effect of sprinklers on reducing the area affected by fire, and found that sprinklers had little effect on fires reaching a size of $3 \mathrm{~m}^{2}$, but reduced the probability of a fire reaching $100 \mathrm{~m}^{2}$ or greater area by $80 \%$ when they worked effectively (Melinek 1993a). Melinek also discussed the potential that less fires may be reported to the fire service in sprinklered buildings. Based on UK data from 1966 to 1972 , it was noted that only $17 \%$ of calls to the fire service from sprinklered buildings were automatic. By assuming that the number of fire starts in industrial buildings was proportional to the product of the number of buildings and the square root of the mean building area, Melinek estimated that the fire services responded to $55 \%$ of the fires in sprinklered buildings that would be expected if the buildings were not sprinklered.

NFPA data from 2003-2007 indicated that sprinklers increased the probability that flame damage was confined to the room of origin to $95 \%$ compared with $74 \%$ for fires in buildings with no sprinkler systems. The fatality rate was $83 \%$ lower in fires in properties protected by sprinkler systems, and total property damage was reduced by 40\%-70\% depending on occupancy (Hall 2010). The 2010 NFPA report also indicates that the "NFPA has no record of a fire killing three or more people in a completely sprinklered building where the system was properly operating". Twenty-five fire s are listed where three or more people have been killed in fully sprinklered properties in the US since 1970. Twenty-two involved an explosion or flash fire and three were a result of firefighting activities.

\section{Uncertainty in estimates of sprinkler system effectiveness}

The range in both sprinkler component and system data collected in this paper shows that there is uncertainty in estimating the effectiveness of sprinkler systems for riskinformed fire safety design. Four studies have included suggested distributions and methodology for including uncertainty in sprinkler system estimates.

(Bukowski et al. 1999) compiled histograms of system effectiveness estimates from a number of studies. Caution was given against using single values for estimating the effectiveness of fire protection systems. Ranges of $88 \%$ to $98 \%$ for commercial systems and $94 \%$ to $98 \%$ for general systems were given by Bukowski.

(Siu and Apostolakis 1988) discussed the uncertainty involved in using expert judgement to estimate the reliability (or "demand availability" as termed in the original paper) of sprinkler systems in specific installations. A Bayesian approach was used to combine small sets of directly relevant incident data with partially relevant data from general populations of sprinklered fire incident data and system test data. Their work also provides techniques to account for and assess an expert's expertise in supplying data estimates. Data from 16 nuclear facility sprinklered fires was supplemented with "expert" data 
represented by Industrial Risk Insurers' sprinkler test data and NFPA sprinklered fire data with associated bias factors to estimate a posterior distribution for the reliability of a sprinkler system in a nuclear facility. The distribution Sui and Apostolakis arrived at for the base case sprinkler reliability in a nuclear facility had a mean reliability of $89 \%$ with a standard deviation of $6 \%$.

(Gravestock 2008) recommended uncertainty distributions for sprinkler system component reliability estimates, as well as upper and lower bounds for system effectiveness. Gravestock noted that where information on distribution shape is unknown, but upper and lower bounds are known, a uniform distribution may be appropriate which assigns equal probability to all potential values within the bounds. If the upper and lower bounds are known and a value of maximum probability is known, a triangular or PERT distribution may be more appropriate. Gravestock recommended using a mean effectiveness of $90 \%$ for sprinkler systems in apartments and 95\% for sprinkler systems in offices, with lower bounds ranging from $46 \%$ to $89 \%$ and upper bounds ranging from $97 \%$ to $99 \%$.

(Frank et al. 2012) estimated the uncertainty in sprinkler effectiveness reported in New Zealand Fire Service fire incident reports from 2001 to 2010 . Probability distributions for sprinkler effectiveness from the reported data were developed using a decision tree approach. Sprinkler system effectiveness based on the reported data was estimated to be $86 \%$ with a standard deviation of $4.6 \%$, using a normal distribution. Ambiguous reporting noted in the fire incident data was a major source of uncertainty in estimating sprinkler effectiveness from this data.

\section{Comparing component-based studies with system-based studies}

While it is difficult to directly compare component-based studies and system-based studies, a number of observations can be made. First, the majority of failures reported in real fires are due to the system being shut off, an inappropriate system, and manual intervention and these failures are not generally captured in component-based studies, although some component-based studies attempt to. One example is the study by Moelling et al, which does discuss the probability of inadvertently closed valves (Moelling et al. 1980). Second, component-based studies may capture some reasons for ineffective operation, such as not enough water released in the case of a pump not operating, but again, the majority of reasons such as partial systems, inappropriate systems, or manual intervention are not captured in component-based approaches. However, component-based studies may capture failures for lack of maintenance or damaged components. While data for the exact components used may not be available, the use of a component-based approach allows reliability estimates for the specific set of compo- nent types used in an individual sprinkler system to be combined.

In most cases, studies presenting sprinkler system component data do not elaborate on the failure modes considered. Other than a few exceptions, component reliability is generally considered to be binary, either the component operates successfully or it fails completely. Correlations between the failure of components are not considered: for example, it is possible that multiple components may fail simultaneously or in close succession, particularly if poor maintenance practices are employed. Thus estimating overall system effectiveness from component-based data is difficult.

System-based studies, by their nature, provide the best average estimates of overall sprinkler system effectiveness. However, since fires are relatively rare events, systembased studies often do not provide detailed information on specific types of sprinkler systems, specific sprinkler system configurations, or other systems present. Fires occur in all ages of buildings, so even new fire incident data includes old sprinkler system designs. In general, the specifications or standard that the incident sprinkler systems were designed to are not available. Maintenance, inspection, and testing data is also not included, so it is difficult to estimate the effects of these aspects on system effectiveness. General details regarding the building of fire origin such as size, geometry, and construction may not be documented and changes to the building use and hazard between the time of design and the incident are not likely to be recorded. Thus it is difficult to estimate how system improvements such as upgraded water supplies or piping networks, or improved inspection, maintenance, and testing practices, will improve system effectiveness from system-based studies. In addition, determining whether a sprinkler system operated effectively or not and the reasons why it may or may not have can require subjective judgement on the part of the reporter, which creates uncertainty in the reported outcome.

Given the limited information available, the recommended approach to estimate effectiveness for a specific system is to take a distribution of effectiveness for general sprinkler systems from system-based studies, and to modify using data from component-based studies. The relative contribution of each component to system effectiveness can be estimated from the component data, and then the effect of making a change to the sprinkler system (such as improving the water supply or improving inspection) should then be considered on a comparative basis with the base system rather than on an absolute basis.

\section{Conclusions and recommendations}

Given how common sprinklers are and how long they have been in use in building fire protection it may be surprising how little is known regarding their effectiveness. This 
paper has summarised available sprinkler system component data and effectiveness estimates for sprinkler systems from fire incident data studies, with discussion of the relative merits of each approach and the uncertainty involved.

A number of recommendations can be made for estimating the effectiveness of a sprinkler system for performance-based design. Due to the majority of sprinkler failures being related to human error, componentbased study data should not be used exclusively without comparison to system-based study data. Adjusting sprinkler system effectiveness due to a system modification such as additional water supplies or valve monitoring should be based on an estimate of the number of failures observed in real fire incidents that would be prevented by the proposed change. The modified effectiveness for the system change can be supported by component-based data.

One potential application of fire incident system-based historical studies is that they be used to test the capability of models such as fault trees. However, the variations that exist between the two approaches mean such comparisons cannot easily be made. The limited data available and subjective nature of fire incident data precludes the use of a single point value for sprinkler effectiveness in performance-based fire safety design. A range of values with associated probabilities should be used to appropriately represent the uncertainty in estimating sprinkler effectiveness from available data. The sensitivity of the proposed fire safety design to the uncertainty in the sprinkler system effectiveness should be investigated.

For an estimate of the effectiveness of general fire sprinkler systems, the available data indicates that a range of sprinkler system effectiveness from a minimum of $70 \%$ to a maximum of $99.5 \%$ may be possible, or ineffective sprinkler operation in a range from 3 in 10 fires to 1 in 200 . The highest probability of sprinkler system effectiveness appears to be between $90 \%$ and $95 \%$ or between 1 in 10 and 1 in 20 ineffective sprinkler operations in fires. For most design purposes, both the extreme upper and lower limits of reported effectiveness are not likely applicable due to the definitions used for effective sprinkler operation in these studies discussed previously. Data pertaining to the applicable jurisdiction should also be considered with greater weight than data from other jurisdictions due to varying practices of design, installation, maintenance, and inspection. If using a probabilistic model, a uniform, triangular or PERT distribution shape may be the most appropriate to use with a peak between $90 \%$ and $95 \%$ and upper and lower bounds estimated from the applicable studies for the situation being considered. An example of a distribution for sprinkler effectiveness based on New Zealand Fire Service data from 2001-2010 was developed by (Frank et al. 2012), which was normally distributed with a mean of $86 \%$ and a standard deviation of $4.6 \%$, although it was noted that ambiguous reporting contributed to the uncertainty in estimating sprinkler effectiveness from this data.

For future data collection, the definition of effective sprinkler system operation should be made clear when it is being reported as such. Discrete system functions (e.g. notification and suppression) should be clearly separated in the data fields. Less subjective measures such as the number of sprinklers activated as a percentage of the number of sprinklers for which the system was hydraulically designed to supply and the number of sprinklers activated inside and outside the compartment of origin would be useful. Integration with inspection, testing, and maintenance data would be useful to provide information on how these factors influence effectiveness. (Frank et al. 2012) discussed specific recommendations for improving data collection in New Zealand, some of which may be suitable in other jurisdictions.

\section{Competing interests}

The authors declare they have no competing interests.

\section{Authors' contributions}

KF collected and collated the data and prepared the manuscript. NG provided information and insight into New Zealand data. MS helped prepare the manuscript. CM conceived of the study and provided insight. All authors read and approved the final manuscript.

\section{Acknowledgements}

This work was supported by the New Zealand Ministry of Science and Innovation, Building Research Levy, and Department of Building and Housing, and the Natural Sciences and Engineering Research Council of Canada.

\section{Author details}

${ }^{1}$ University of Canterbury, Christchurch, New Zealand. ${ }^{2}$ Aon, 16th Floor, AMP Centre, 29 Customs Street West, Auckland, New Zealand.

Received: 8 November 2012 Accepted: 2 October 2013

Published: 20 October 2013

\section{References}

Baldwin R, North MA (1971) The number of sprinkler heads opening in fires. Fire Research Station Fire Research Note No 886 Borehamwood, UK

Beyler C (1999) State of the art assessment. In: Lucht DA (ed) Proceedings of the Second Conference on Fire Safety Design in the 21st Century, Worcester, MA, USA, June 9-11

Brammer H (2010) Examination into the reliability of secondary water supplies. University of Canterbury Research Report 10/10, Christchurch, NZ, p 152

British Standards Institution (2003) PD 7974-7:2003 - The application of fire safety engineering principles to fire safety design of buildings. Probabilistic Risk Assessment, London, UK

Budnick EK (2001) Automatic sprinkler system reliability. Fire Prot Eng Mag Issue No. 9: 7-12

Bukowski RW, Budnick EK, Schemel CF (1999) Estimates of the operational reliability of fire protection systems. In: Proceedings of the Third International Conference on Fire Research and Engineering, October 4-8 Bethesda, MD, USA, pp 87-98

Croce PA, Grosshandler WL, Bukowski RW, Gritzo LA (2008) The international FORUM of fire research directors: A position paper on performance-based design for fire code applications. Fire Saf J 43(3): 234-236. doi:10.1016/j.firesaf.2007.12.004 
Department of Building and Housing (2005) Determination 2005/109: Single means of escape from a high-rise apartment building. New Zealand Department of Building and Housing, Wellington, NZ

Department of Building and Housing (2012) CNM2 Verification Method: Framework for Fire Safety Design For New Zealand Building Code Clauses C1-C6 Protection from Fire). Department of Building and Housing, Wellington, NZ

Donaldson I, Bach K, Frost T (eds) (2005) International Fire Engineering Guidelines: 2005 Edition. Australian Building Codes Board, Canberra, Australia

Enright T (2003) Impact on life safety of the Type 5 alarm. New Zealand Fire Service Commission Research Report Number 40, Christchurch, NZ, p 57

Feeney M (2001) Accounting for Sprinkler Effectiveness in Performance Based Design of Steel Buildings in Fire. Master's project, University of Canterbury, Christchurch, NZ

Finucane M, Pinkney D (1988) Reliability of fire protection and detection systems. Report Number SRD R431 United Kingdom Atomic Energy Authority Safety and Reliability Directorate, University of Edinburgh, Scotland, p 15

Fleming RP (1998) Analysis of fire sprinkler systems performance in the northridge earthquake. NIST GCR-98-736 National Institute of Standards and Technology, Gaithersburg, MD, USA

Frank K, Spearpoint M, Challands N (2012) Uncertainty in estimating the fire control effectiveness of sprinklers from New Zealand fire incident reports. Fire Technology. doi:10.1007/s10694-012-0297-2

Grant CC (1996) The birth of NFPA. NFPA Journal, Quincy, MA, p 5

Gravestock N (2008) Effectiveness of Fire Safety Systems for Use in Quantitative Risk Assessments. New Zealand Fire Service Commission, Wellington, NZ

Grosshandler W (2006) FORUM Workshop on establishing the scientific foundation for performance-based fire codes: Proceedings. National Institute of Standards and Technology, Gaithersburg, MD, USA, p 55

Hall Jr JR (2006) An analysis of automatic sprinkler system reliability using current data. National Fire Protection Association Quincy, MA, USA, p 19

Hall Jr JR (2007) New statistics of sprinkler reliability and performance. In: Interflam 2007, 11th International Conference on Fire Science and Engineering. University of London, UK, p 10

Hall Jr JR (2010) U.S. Experience with sprinklers and other automatic fire extinguishing equipment. National Fire Protection Association Quincy, MA, USA, p 102

Hall Jr JR (2012) U.S. Experience with sprinklers. NFPA, Quincy, MA, p 79

Hauptmanns U, Marx M, Grunbeck S (2008) Availability analysis for a fixed wet sprinkler system. Fire Safety Journal 43: 468-476. doi:10.1016/j.firesaf.2008.03.002

Houston B, Mak C (2010) Christchurch's earthquake, wil this shake up the sprinkler industry?. Presented at the 2010 Fire-NZ Conference, November 4, 2010, Christchurch, NZ

Hughes Associates Incorporated (1998) Pilot study: Automatic sprinkler system reliability analysis. Hughes Associates, Baltimore, MDS, p 82

Juneja CS (2004) Analysis of Ontario fires and reliability of active fire protection systems. Master's thesis, Carleton University, Ottawa, ON, p 353

Knudsen R, Bygbjerg H (2009) Reliability of automatic water sprinkler systems. Danish Institute of Fire and Security Technology, Hvidovre, Denmark, p 12

Koffel WE (2005) Reliability of automatic sprinkler systems (revised). accessed from http://www.nfpa.org/ /media/Files/proceedings/ reliabilityofautomaticsprinklersystemswkoffelpaper.pdf on October 16 2011, p 8

Lees FP (2005) Lee's Loss Prevention in the Process Industry: Hazard Identification, Assessment, and Control. Elsevier, Amsterdam

Linder KW (1993) Field reliability of fire detection systems. In: NIST 5264: Balanced Design Concepts Workshop, National Institute of Standards and Technology. Gaithersburg, MD, June 30 - July 2

Marryatt HW (1988) Fire: A Century of Automatic Sprinkler Protection - Revised. Australian Fire Protection Association, Melbourne, Australia

Melinek SJ (1993a) Effectiveness of sprinklers in reducing fire severity. Fire Saf J 21(4): 299-311. doi:10.1016/0379-7112(93)90018-L

Melinek SJ (1993b) Potential value of sprinklers in reducing fire casualties. Fire Saf J 20: 275-287. doi:10.1016/0379-7112(93)90048-U

Miller MJ (1974) Reliability of fire protection systems. Chem Eng Prog 70(4): 62-67

Moelling DS, Sideris AG, Hockenbury RW (1980) Reliability of fire protection systems in nuclear plants. Thermal Reactor Safety, in Proceedings of the
American Nuclear Society/European Nuclear Society Topical Meeting Knoxville, TN, April 6-9

Moinuddin K, Thomas I, Chea S (2009) Estimating the reliabilty of sprinkler systems in australian high-rise office buildings. Fire Safety Science 9: 515-526. doi:10.3801/IAFSS.FSS.9-515

Nash P, Young RA (1991) Automatic Sprinkler Systems for Fire Protection, 2nd edn. Paramount Publishing Limited, Borehamwood, UK

New York State Factory Investigating Commission (1912) Preliminary report of the factory investigating commission New York, NY, p 815, http://www. archive.org/details/preliminaryrepor01newyiala

Notarianni KA, Fischbeck PS (1999) Dealing with uncertainty to improve the regulatory system. In: Lucht DA (ed) Proceedings of the Second Conference on Fire Safety Design in the 21st Century, Worcester, MA, USA, June 9-11

Powers WR (1979) Sprinkler experience in high-rise buildings (1969-1979). Technology Report 79-1 Society of Fire Protection Engineers, Boston, Massachusetts, $\mathrm{p} 7$

Richardson JK (1985) CBD-238. The reliability of automatic sprinkler systems. National Research Council of Canada, Ottawa, ON, p 3. http://archive.nrccnrc.gc.ca/eng/ibp/irc/cbd/building-digest-238.html

Rohr KD, Hall Jr JR (2005) U.S. Experience with Sprinklers and other Fire Extinguishing Equipment. National Fire Protection Association, Quincy, MA, p 72

Ronty V, Keski-Rahkonen O (2004) Reliabilty of sprinkler systems: Exploration and analysis of data from nuclear and non-nuclear installations. VTT Working Papers Number 15 VTT Building Technology, Espoo, Finland, p 100

Sakenaite J (2009) The problem of sprinkler reliability. Science - Future of Lithuania 1(5): 34-40

Sekizawa A, Ebihara M, Notake H (2003) Development of seismic-induced fire risk assessment method for a building. Fire Saf Sci 7: 309-320. doi:10.3801/IAFSS.FSS.7-309

SINTEF (2009) OREDA Offshore Reliability Data, vol 1, 5th edn. Offshore Reliability Data Organisation, Trondheim, Norway

Siu N, Apostolakis G (1988) Uncertain data and expert opinions in the assessment of the unavailability of suppression systems. Fire Tech 24(2): 138-162. doi:10.1007/BF01041339

Smith F (1983) How successful are sprinklers. Soc Fire Prot Eng Bull 2: 1-11

Standards New Zealand (2007) NZS 4541:2007 - Automatic Fire Sprinkler Systems, Wellington, NZ

Taylor KT (1990) Office building fires... A case for automatic fire protection. Fire J 84(1): 52-54

Thomas IR (2002) Effectiveness of fire safety components and systems. J Fire Prot Eng 12(2): 63-78. doi:10.1177/1042391502012002784

Thomas IR, Bennetts ID, Poon SL, Sims JA (1992) The Effect of Fire in the Building at 140 William Street. BHP Research, Melbourne, Aus

Todd D, Carino N, Chung RM, Lew HS, Taylor AW, Walton WD (1994) NISTIR 5396:1994 Northridge earthquake performance of structures, lifelines, and fire protection systems. National Institute of Standards and Technology, Gaithersburg, MD, USA, p 171

Tryon GH, McKinnon GP (eds) (1969) Fire Protection Handbook, 13th edn. National Fire Protection Association, Quincy, MA

US Department of Energy (2004) Summary of fire protection programs for calendar year 2004. US Department of Energy, Washington, DC, p 21

Watanabe A (1979) Effectiveness of active fire protection systems. Systems Approach to Fire Safety in Buildings, Volume II CIB Symposium, August 29 and 30:1-11

Yung D, Benichou N (2000) Consideration of reliability and performance of fire protection systems in FiRECAM. NRCC-44001 National Research Council of Canada, Ottawa, ON, Canada, p 12

doi:10.1186/2193-0414-2-6

Cite this article as: Frank et al:: A review of sprinkler system effectiveness studies. Fire Science Reviews 2013 2:6. 